\title{
Survival of patients with advanced metastatic melanoma: the impact of novel therapies-update 2017
}

DOI:

10.1016/j.ejca.2017.06.028

10.1016/j.ejca.2017.06.028

\section{Document Version}

Accepted author manuscript

Link to publication record in Manchester Research Explorer

\section{Citation for published version (APA):}

Ugurel, S., Röhmel, J., Ascierto, P. A., Flaherty, K. T., Grob, J. J., Hauschild, A., Larkin, J., Long, G. V., Lorigan, P., McArthur, G. A., Ribas, A., Robert, C., Schadendorf, D., \& Garbe, C. (2017). Survival of patients with advanced metastatic melanoma: the impact of novel therapies-update 2017. European Journal of Cancer, [PMID 28756137]. https://doi.org/10.1016/j.ejca.2017.06.028, https://doi.org/10.1016/j.ejca.2017.06.028

Published in:

European Journal of Cancer

\section{Citing this paper}

Please note that where the full-text provided on Manchester Research Explorer is the Author Accepted Manuscript or Proof version this may differ from the final Published version. If citing, it is advised that you check and use the publisher's definitive version.

\section{General rights}

Copyright and moral rights for the publications made accessible in the Research Explorer are retained by the authors and/or other copyright owners and it is a condition of accessing publications that users recognise and abide by the legal requirements associated with these rights.

\section{Takedown policy}

If you believe that this document breaches copyright please refer to the University of Manchester's Takedown Procedures [http://man.ac.uk/04Y6Bo] or contact uml.scholarlycommunications@manchester.ac.uk providing relevant details, so we can investigate your claim.

\section{OPEN ACCESS}




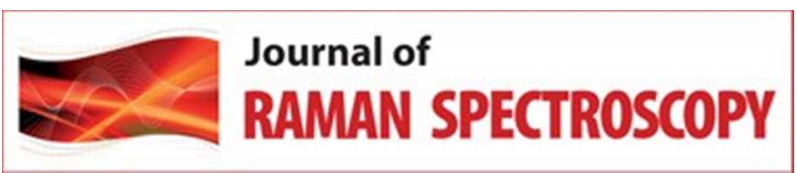

\section{Raman Spectroscopy as a Novel Method in Placental Research: Recognizing the Pattern of Placental Hypoxia}

\begin{tabular}{|c|c|}
\hline Journal: & Journal of Raman Spectroscopy \\
\hline Manuscript ID & JRS-17-0084.R2 \\
\hline Wiley - Manuscript type: & Short Communication \\
\hline Date Submitted by the Author: & $\mathrm{n} / \mathrm{a}$ \\
\hline Complete List of Authors: & $\begin{array}{l}\text { Schlabritz-Loutsevitch, Natalia; Texas Tech University Health Sciences } \\
\text { Center at the Permian Basin, Obstetrics and Gynecology } \\
\text { Gandhi, Kushal; Texas Tech University Health Sciences Center at the } \\
\text { Permian Basin, Obstetrics and Gynecology } \\
\text { Soydemir, Fatimah; University of Manchester, Maternal and Fetal Medicine } \\
\text { Health Research Centre } \\
\text { Brownbill, Paul; University of Manchester, Maternal and Fetal Health } \\
\text { Research Centre } \\
\text { Sengar, Raghvendra; Methrohm USA, Spectroscopy Sales } \\
\text { Ventolini, Gary; Texas Tech University Health Sciences Center at the } \\
\text { Permian Basin, Obstetrics and Gynecology } \\
\text { Bruillard, Paul; Pacific Northwest National Laboratory, Computational } \\
\text { Mathematics } \\
\text { Gosink, Luke; Pacific Northwest National Laboratory, Computational } \\
\text { Mathematics }\end{array}$ \\
\hline Keywords: & Raman Spectroscopy, Placenta, hypoxia, pattern recognition \\
\hline
\end{tabular}


1

2

4

5

6

6

7 8 9 10

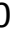

1

2

3

4

\section{SHORT COMMUNICATION}

\section{RAMAN SPECTROSCOPY AS A NOVEL METHOD IN PLACENTAL RESEARCH: RECOGNIZING THE PATTERN OF PLACENTAL HYPOXIA}

Natalia Schlabritz-Loutsevitch ${ }^{1}{ }^{*}$, Kushal Gandhi $^{1}$, Fatimah Soydemir ${ }^{2,3}$, Paul Brownbill ${ }^{2,3}$, Raghvendra Sengar ${ }^{4}$, Gary Ventolini ${ }^{1}$, Paul Bruillard ${ }^{5}$ and Luke Gosink ${ }^{5}$.

${ }^{1}$ Texas Tech University Health Sciences Center at the PB, Odessa, TX, USA

${ }^{2}$ Maternal and Fetal Health Research Centre, School of Medical Sciences, Faculty of Biology, Medicine \& Health, University of Manchester, St. Mary's Hospital, Oxford Road, Manchester, M13 9WL UK

${ }^{3}$ Maternal and Fetal Health Research Centre, St. Mary's Hospital, Central Manchester University Hospitals NHS Foundation Trust, Manchester Academic Health Science Centre, Manchester M13 9WL, UK

${ }^{4}$ Metrohm, USA

${ }^{5}$ Pacific Northwest National Laboratory, Richland, WA, USA

\section{*Corresponding author}

Natalia Schlabritz-Lutsevich MD, PhD

Research Associate Professor (tenure-track)

Department of Obstetrics and Gynecology

Department of Pharmacology and Neuroscience

Texas Tech University HSC School of Medicine

e-mail: Natalia.schlabritz-lutsevich@ttuhsc.edu

office phone: 432-703-5169

cell phone: $210-317-0156$

fax: 432-335-5140 


\section{ABSTRACT}

37 Raman spectroscopy (RS) is a non-elastic photon scattering technique. We evaluated whether a 38 specific RS pattern exists in fetal venous perfusates obtained at 30-60 min intervals from the ex 39 vivo human dual placental perfusion model under hypoxic $(\mathrm{n}=6)$ and normoxic $(\mathrm{n}=5)$ conditions. 40 A stratified Principle Component and a linear support vector machine analyses showed that the 41 separation between two conditions was readily feasible at 60-120 min of perfusion; after this any 42 apparent differences were most likely the result of artifact over-fitting. This report is the first 43 attempt to identify the RS fingerprint associated with placental hypoxia.

44

45 Keywords: Raman spectroscopy, placenta, hypoxia, pattern recognition.

46

47

48

49

50

51

52

53

54

55

56

57 


\section{INTRODUCTION}

59 In the $21^{\text {st }}$ century diagnostic methods expanded beyond the identification of single molecular

60 species ${ }^{[1]}{ }^{[2]}$. Raman Spectroscopy (RS), a method based on inelastic light scattering when

61 excitation photons interfere with specific molecular bonds ${ }^{[3]}$, represents a unique tool currently

62 being applied to the diagnosis of cancer, Alzheimer and cardio-vascular diseases ${ }^{[4]}{ }^{[5]}$. Resonance

$63 \mathrm{RS}$ and Raman microspectroscopy have been applied for detection of hemo-and myo-globin

64 oxygenation for monitoring of tissue oxygenation ${ }^{[6]}[6-7]$ and for molecular fingeprints of pre-

65 eclamptic placentas ${ }^{[8]}$. Orbital Raster Scanning (ORS) is a novel RS sampling technique based on

66 rastering laser beam, which repetitively sweeps the sample volume providing the opportunity to

67 represent thousands of chemical compounds simultaneously within a spectral "fingerprint". The

68 rastering approach allows scan the larger area, e.g. while the focused laser beam, has a diameter

69 of $50 \mu \mathrm{m}$, the raster spot diameter is approximately $1 \mathrm{~mm}$. This gives an ORS sampling area of

70 approximately $0.076 \mathrm{~mm}^{2}$ versus an instantaneous sampling area of $0.0078 \mathrm{~mm}^{2}$. ${ }^{[9]}$ The

71 application of mathematical models of pattern recognition enables an analysis between

72 experimental study groups. Here we demonstrate, for the first time, the application of RS-ORS to

73 detect fetal hypoxia in physiological perfusates following the adaptation of the ex vivo dual

74 perfused human placenta to different oxygenation conditions.

\section{MATERIALS AND METHODS}

76 We analyzed $500 \mu \mathrm{L}$ of fetal perfusate, obtained using the human ex vivo dual placental

77 perfusion technique, which had been modified to normoxic $(\mathrm{N} ; \mathrm{n}=5)$ and hypoxic $(\mathrm{H} ; \mathrm{n}=6)$

78 conditions, with mean soluble oxygen tension within the intervillous space (IVS) of 5-7\% and $<$

$793 \%$, respectively ${ }^{[10]}$. These adaptations have been proven to have specific changes in 
80 inflammatory mediation within the perfused tissue, demonstrated as an altered biochemical

81 release of cytokines ${ }^{[10 a]}$. The perfusate (modified Earle' bicarbonate buffer) composition was as

82 follows $2.4 \mathrm{mM} \mathrm{CaCl2} ; 0.4 \mathrm{mM} \mathrm{MgSO} ; ; 117 \mathrm{mM} \mathrm{NaCl} ; 5.4 \mathrm{mM} \mathrm{KCl} ; 0.41 \mathrm{mM} \mathrm{NaH2PO}$;

$8326 \mathrm{mM} \mathrm{NaHCO}$; 5.6mM D-glucose; 5,000 IU heparin, sodium; 0.04mM L-arginine; 0.1\% (w/v)

84 bovine serum albumin (fraction IV); 3.5\% (w/v) dextran (clinical grade; 70KDa ${ }^{[10 b]}$. Fetal

85 venous perfusate samples were collected at $60,120,150,210,240,300$, and 330 minutes

86 (Supplementary material, Fig. 1S). The RS of the samples were collected using Mira Cal

87 software (Mira M-1, Metrohm, USA), which was connected to the hand-held RS device (Mira

88 M-1, Metrohm, USA). In MIRA M1 device, exposure time is automated be the analyzer, the 89 exposure time was 5 second with spectral resolution: 14 to $16 \mathrm{~cm}^{-1}$.

Insert Fig. 1 here

91 For the Principal component analyses the spectral analysis began by constructing a tuple of 92 information from the twelve fingerprint regions, identified by picking maximum peak heights for 93 peaks that were greater than the mean value of all spectra values (Fig 1). For each of these 94 regions, a feature vector was constructed based on three peak attributes: the peak's value (x), the 95 derivative for the peak ( $\left.\mathrm{x}^{\prime}\right)$, and the second derivative for the peak ( $\left.\mathrm{x}^{\prime \prime}\right)$. Thus for a given time 96 (min) and class (i.e., $\mathrm{H}$ vs. N), a 36 dimensional feature vector was constructed (i.e. 12 peaks 97 times, 3 attributes per peak).

98 A stratified Principle Component Analysis (PCA) ${ }^{[11]}$ was performed independently on the 99 feature vector data aggregated at each time point. For each time point, a set of distinct principle 100 components were identified where each subsequent set of components describes an increasing 101 amount of variance in the feature vector data: e.g., $50 \%, 60 \%, \ldots, 100 \%$. A linear support vector 
102 machine $(\mathrm{SVM})^{[12]}$ was then used to compute the accuracy of each component set. In this 103 context, the analysis contrasts how increasing information content (as represented by different 104 principle components) impacts classification performance.

\section{RESULTS AND DISCUSSION}

107 Twelve Raman peaks were detected at $415 \mathrm{~cm}^{-1}, 440 \mathrm{~cm}^{-1}, 541 \mathrm{~cm}^{-1}, 785 \mathrm{~cm}^{-1}, 851 \mathrm{~cm}^{-1}, 920 \mathrm{~cm}^{-}$ $108{ }^{1}, 1020 \mathrm{~cm}^{-1}, 1086 \mathrm{~cm}^{-1}, 1129 \mathrm{~cm}^{-1}, 1341 \mathrm{~cm}^{-1}, 1457 \mathrm{~cm}^{-1}, 1632 \mathrm{~cm}^{-1}$ (Fig.1S). The hypoxic 109 treatment of placenta ex vivo in our study represents the models, mimicking pre-eclampsia (PE) $110{ }^{[10 a]}$, interestingly, these spectra are similar to the Raman shift, reported for human normal and 111 pre-eclamptic placentas ${ }^{[8]}$ and blood samples from women with pre-eclampsia ${ }^{[13]}$. The Raman 112 peak of $1129 \mathrm{~cm}^{-1}$ was quite close to $1127 \mathrm{~cm}^{-1}$ hemoglobin-derived hemoporfirin shift reported 113 in exposed to hypoxia erythrocytes and myocardium ${ }^{[6,14]}$ and the same as found in placentas 114 from women with pre-eclampsia ${ }^{[8]} .1128 \mathrm{~cm}^{-1}$ Raman shift was identified for myristic acid, 115 which has also chain vibration expansion shift of $414 \mathrm{~cm}^{-1[15]}$ - close to detected in our study 415 $116 \mathrm{~cm}^{-1}$. Band at the shift of $1341 \mathrm{~cm}^{-1}$ had decreased intensity in samples with hypoxia in our study 117 and is similar to reported $1342 \mathrm{~cm}^{-1}$ shift with decreased intensity in serum of women with PE, 118 which has been identified as $\mathrm{CH}$ bending of amino acids ${ }^{[13]}$. The $1457 \mathrm{~cm}^{-1}$ shift is located within 119 1420-1500 $\mathrm{cm}^{-1}$ region of described deformities for $\delta\left(\mathrm{CH}_{2}\right)$ and $\delta\left(\mathrm{CH}_{3}\right)$ region of L-arginine ${ }^{[15]}$. 120 The peak of $440 \mathrm{~cm}^{-1}$ corresponds to $\beta$-D-glucose and peak at $541 \mathrm{~cm}^{-1}$-to $\mathrm{D}(+)$ dextrose ${ }^{[15]}-$ 121 components of the perfusion media. At the 60 min time point the separation between $\mathrm{N}$ and $\mathrm{H}$ 122 (Figure 2A) is easily obtained with 100\% accuracy using principle components that capture $80 \%$ 
123 of the variability in the feature vector data. Even when using fewer features where $50 \%$ of the

124 variability is captured, separation is feasible with $80 \%$ accuracy.

125

Insert Fig. 2 here

126 At 120 minutes (Figure 2B), a slight degradation in accuracy is observed. Specifically, we now 127 need almost $88 \%$ of the variance captured by the principle components to provide $100 \%$ 128 accuracy in separating two conditions (as opposed to $80 \%$ seen in 60 minutes). Additionally, 129 classifying based on PCA that captures $50 \%$ of the variance only provides about $75 \%$ accuracy.

130 Beyond 120 minutes (Figure 2C and D), significant degradation of the differential signal is 131 observed. Though 100\% classification accuracy is feasible (i.e. using principle components that 132 capture all variance in data), removing even a little of the information in the data (i.e. from $95 \%$ 133 to $100 \%$ ) dramatically reduces accuracy. Such behavior strongly indicates that beyond 120 134 minutes of perfusion, separation between two conditions is an artifact of overfitting or could 135 mirror the phenomenon of slow progression of normoxia toward hypoxia in the artificial ex vivo 136 perfusion system ${ }^{[10 \mathrm{~b}]}$. To more confidently address this artifact and confirm the ability (or 137 inability) to separate data beyond 120 minutes, an additional number of samples is required. 138 Commensurate with a reduction in classification accuracy after the 120 minute time point 139 between normoxic and hypoxic groups, the fetal-side release profile of endogenous placental 140 substances appears to be strongly governed by intervillous space soluble oxygenation within this 141 timeframe, since the difference in this variable is highest within the first two hours and 142 diminishes thereafter ${ }^{[10 b]}$. Raman spectra are produced by the portion of photons, scattered by 143 electron density of specific molecular bonds ${ }^{[5 \mathrm{a}]}$ and depend on vibrational activity of the bonds. 144 Therefore, it is also possible that the intervillous space hypoxia results in the differences in 
145 vibrational activity of the bonds, prior to the release of any active substances in the fetal

146 circulation and therefore could be a sensitive method of diagnosis of fetal hypoxia.

\section{ACKNOWLEDGEMENTS}

148 We are indebted to the Department of Obstetrics and Gynecology (Department Chair Dr. Moss 149 Hampton) for the continuous support.

\section{FIGURE LEGENDS}

151 Figure 1. Example of representative peaks used for the vector construction.

152 Figure 2. The accuracy of a linear support vector machine to separate hypoxia from normoxia at $15360,120,150$ and 210 min of the placental perfusion ex vivo.

154

155

156

157

158

159

160

161

162

163

164

165

166

167

168

169

170

171

172

173

174

175

176

177

178

179

\section{SUPPLEMENTARY MATERIAL}

Figure 1S. Mean Raman Spectroscopy patterns in the fetal perfusates obtained at 30-60 min intervals in ex vivo placental perfusion: hypoxic $(n=6)$ and normoxic $(n=5)$ conditions ${ }^{[10 b]}$.

\section{REFERENCES}

[1] F. Mousavi, B. Bojko and J. Pawliszyn, Anal Chim Acta 2015, 892, 95-104.

[2] J. Peng, F. Tang, R. Zhou, X. Xie, S. Li, F. Xie, P. Yu and L. Mu, Acta Pharm Sin B 2016, 6, 540-551.

[3] M. Jermyn, J. Desroches, K. Aubertin, K. St-Arnaud, W. J. Madore, E. De Montigny, M. C. Guiot, D.

Trudel, B. C. Wilson, K. Petrecca and F. Leblond, Phys Med Biol 2016, 61, R370-r400.

[4] K. Kong, C. Kendall, N. Stone and I. Notingher, Adv Drug Deliv Rev 2015, 89, 121-134.

[5] a) I. Pence and A. Mahadevan-Jansen, Chem Soc Rev 2016, 45, 1958-1979; b) C. R. Kong, I. Barman, N.

C. Dingari, J. W. Kang, L. Galindo, R. R. Dasari and M. S. Feld, AIP Adv 2011, 1, 32175.

[6] A. Almohammedi, S. M. Kapetanaki, B. R. Wood, E. L. Raven, N. M. Storey and A. J. Hudson, J R Soc Interface 2015, 12.

[7] a) K. R. Ward, I. Torres Filho, R. W. Barbee, L. Torres, M. H. Tiba, P. S. Reynolds, R. N. Pittman, R. R. Ivatury and J. Terner, Crit Care Med 2006, 34, 792-799; b) I. P. Torres Filho, J. Terner, R. N. Pittman, E. Proffitt and K. R. Ward, J Appl Physiol (1985) 2008, 104, 1809-1817.

[8] S. J. Chen, Y. Zhang, X. P. Ye, K. Hu, M. F. Zhu, Y. Y. Huang, M. Zhong and Z. F. Zhuang, Arch Gynecol Obstet 2014, 290, 943-946.

[9] P. A. Mosier-Boss and M. D. Putnam, Anal Chem Insights 2013, 8, 83-97.

[10] a) A. Jain, H. Schneider, E. Aliyev, F. Soydemir, M. Baumann, D. Surbek, M. Hediger, P. Brownbill and C. Albrecht, Lab Invest 2014, 94, 873-880; b) F. Soydemir, S. Kuruvilla, M. Brown, W. Dunn, P. Day, I. P. Crocker, P. N. Baker, C. P. Sibley and P. Brownbill, Lab Invest 2011, 91, 181-189.

[11] H. Abdi, Williams, L.J. , Wiley Interdisciplinary Reviews: Computational Statistics 2010, 2, 433-459.

[12] V. V. Corinna Cortes, Machine Learning 1995, 20, 273-297. 
180 [13] U. P. Günay Başar, Şeyma Şeninak, Tuba Günel, Ali Benian, and Ibrahim Kalelioğlu Spectroscopy: An 181 International Journal 2012, 27, 14.

182 [14] V. Revin, I. Grunyushkin, N. Gromova, E. Revina, A. S. A. Abdulvwahid, I. Solomadin, A. Tychkov and 183 A. Kukina, Biotechnology \& Biotechnological Equipment 2017, 31, 128-137.

184 [15] J. De Gelder, K. De Gussem, P. Vandenabeele and L. Moens, Journal of Raman Spectroscopy 2007, $18538,1133-1147$.

186 


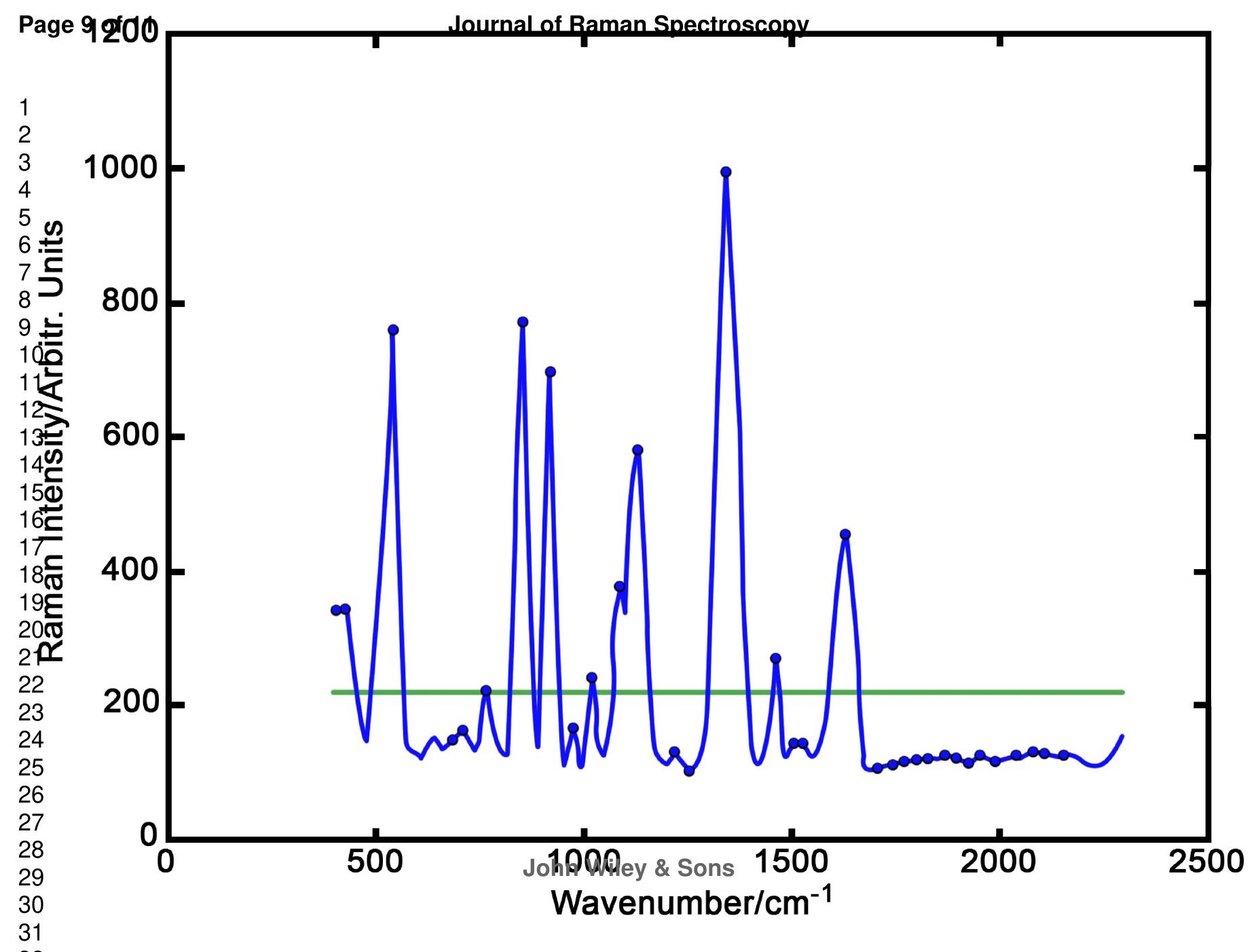




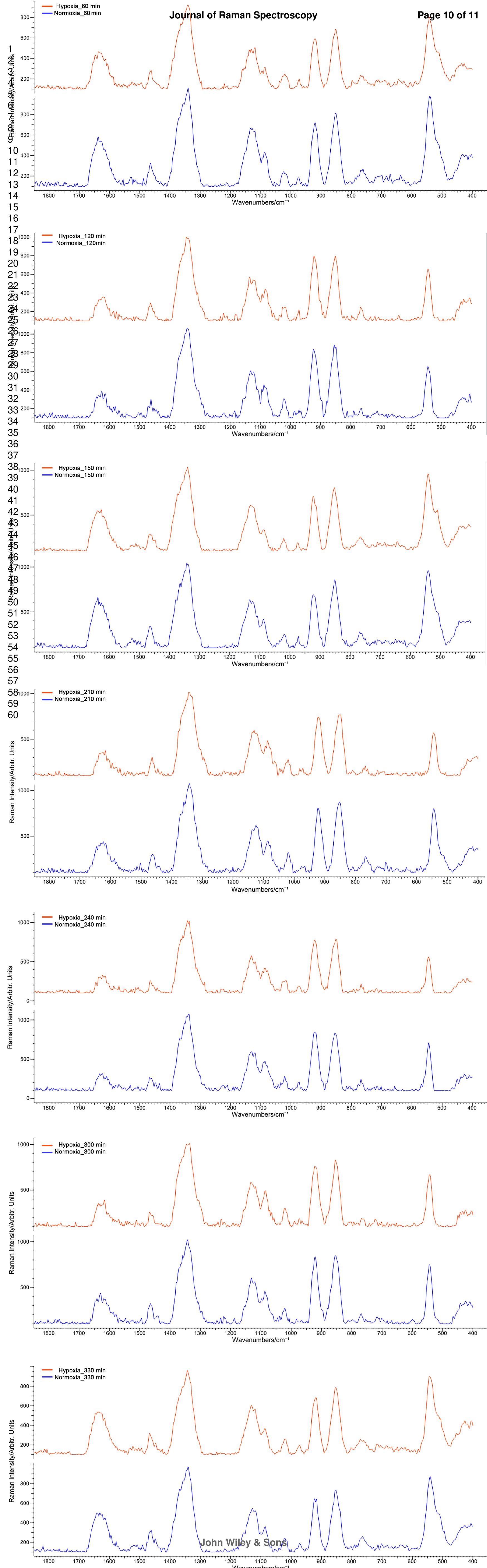



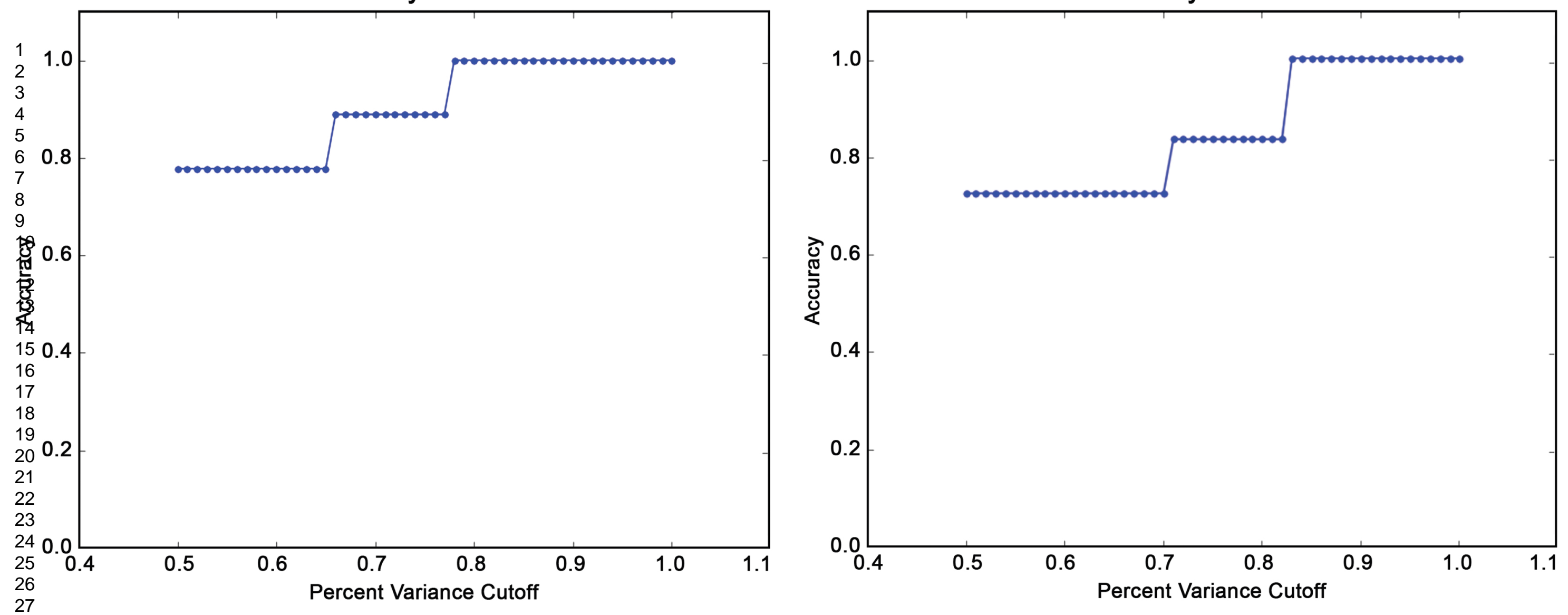

Accuracy at $150 \mathrm{~min}$

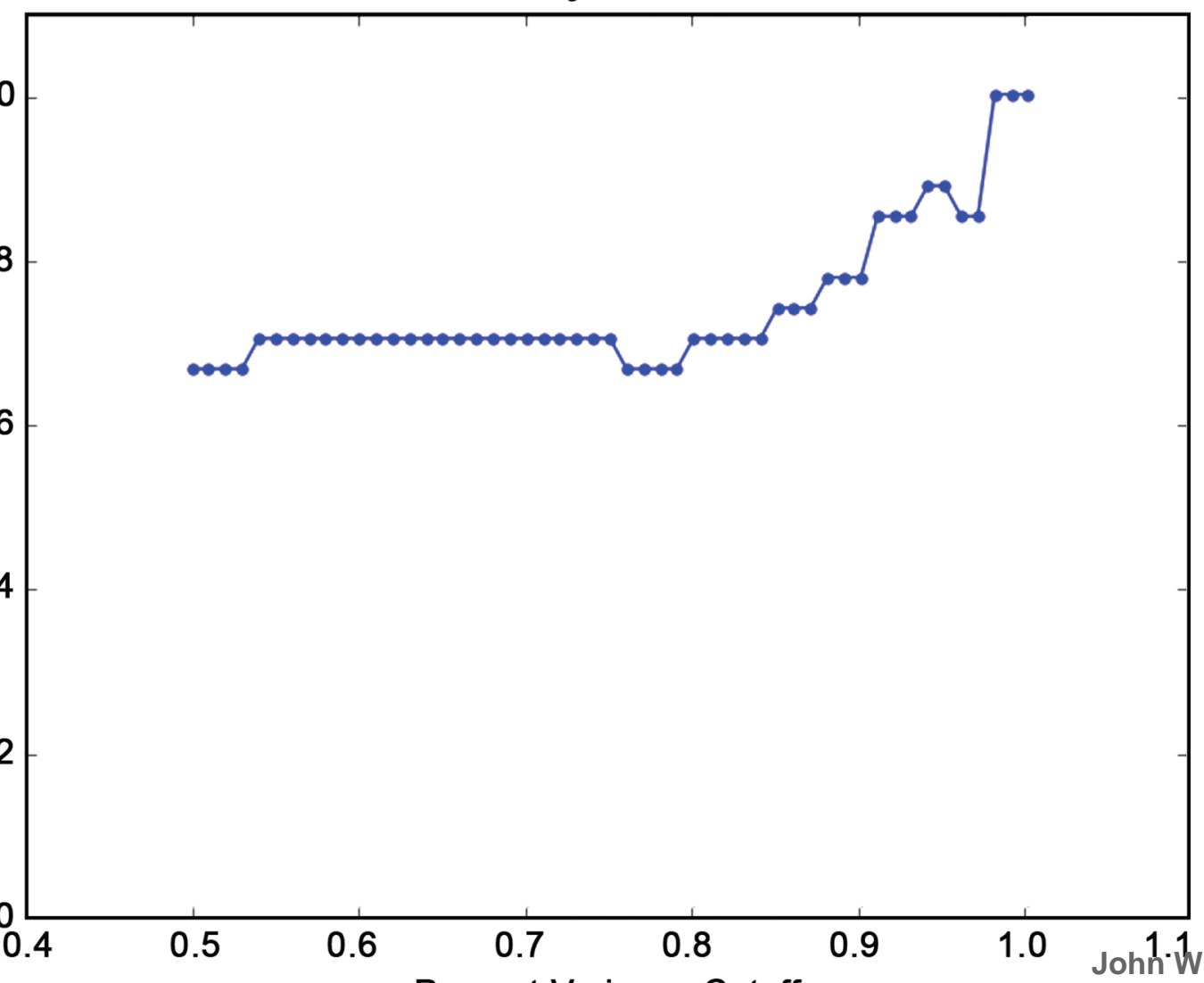

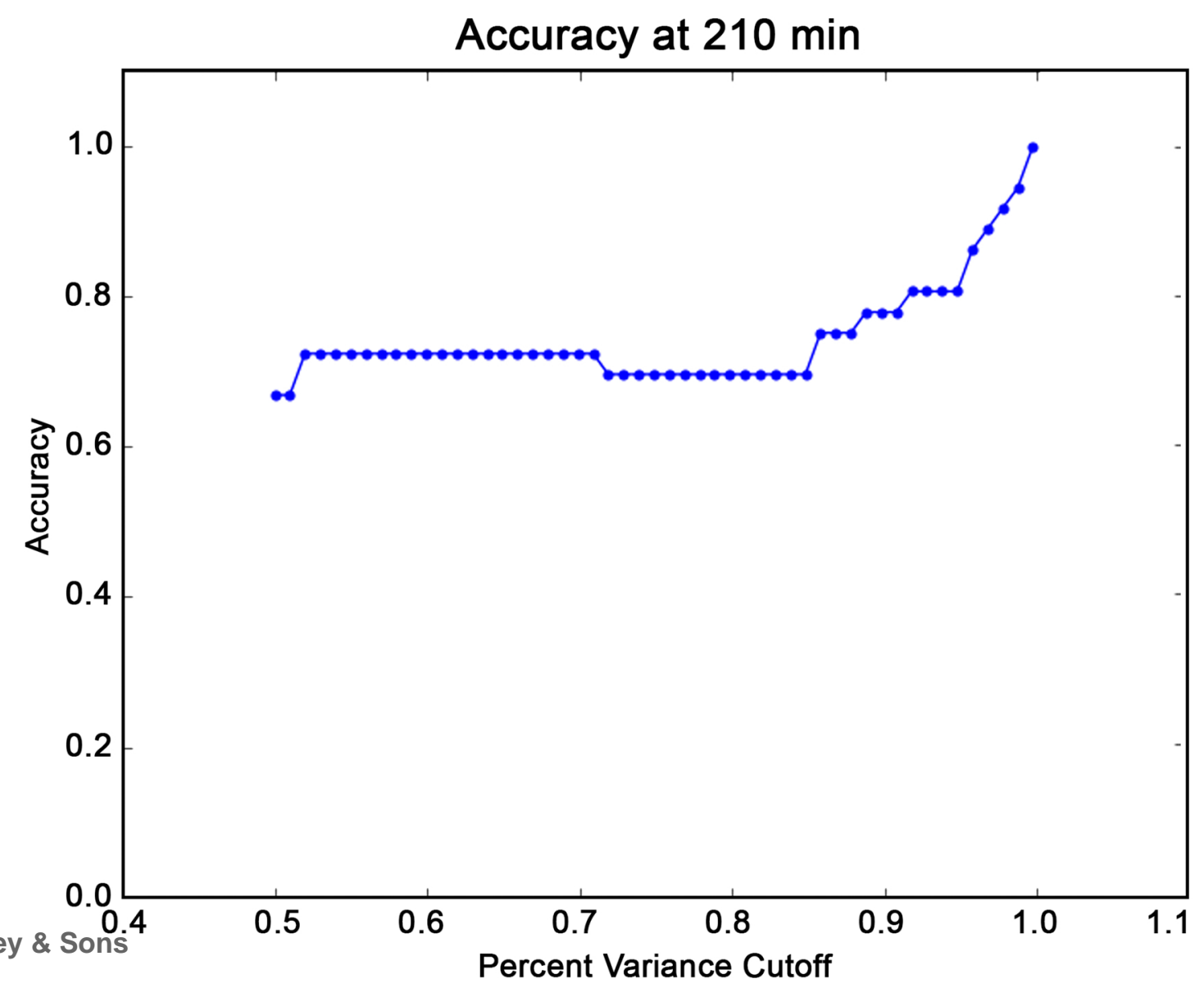

